\title{
Effect of preoperative warming during cesarean section under spinal anesthesia
}

\author{
Sung Hee Chung ${ }^{1}$, Byung-Sang Lee ${ }^{1}$, Hyeon Jeong Yang ${ }^{2}$, Kyoung Seok Kweon ${ }^{1}$, Huyn-Hea Kim , \\ Jieun Song ${ }^{2}$, and Dong Wook Shin ${ }^{2}$ \\ Department of Anesthesiology and Pain Medicine, 'CHA Gumi Medical Center, CHA University, Gumi, \\ ${ }^{2}$ CHA Bundang Medical Center, CHA University, Seongnam, Korea
}

Background: Postoperative hypothermia and shivering is a frequent event in patients during cesarean section under spinal anesthesia. We assessed the effect of preoperative warming during cesarean delivery under spinal anesthesia for prevention of hypothermia and shivering.

Methods: Forty five patients undergoing elective cesarean section were randomly assigned to three groups. Group F received warmed intravenous fluid $\left(40^{\circ} \mathrm{C}\right)$. Group A patients were actively warmed by forced air-warming. Group $\mathrm{C}$ was the control group. Forced air-warming and warmed fluid was maintained for the 15 min preceding spinal anesthesia. Core temperature (tympanic membrane) and the skin temperature of arm and thigh were measured and shivering was graded simultaneously.

Results: The core temperature at 45 min decreased less in Groups $\mathrm{F}$ and A than Group $\mathrm{C}\left(-0.5^{\circ} \mathrm{C} \pm 0.3^{\circ} \mathrm{C}\right.$ vs $-0.6^{\circ} \mathrm{C}$ $\pm 0.4^{\circ} \mathrm{C}$ vs $-0.9^{\circ} \mathrm{C} \pm 0.4^{\circ} \mathrm{C}$, respectively; $\left.\mathrm{P}=0.004\right)$. The arm temperature at $15 \mathrm{~min}$ and $30 \mathrm{~min}$ exhibited a greater increase in Group A than Group F and Group C ( $\mathrm{P}=0.001$ and $\mathrm{P}=0.012$, respectively). Leg temperature increased similarly among the three groups. The incidence of shivering was significantly less in Group A and Group F than Group C (20\%, 13.3\%, and 53.3\%, respectively; $\mathrm{P}=0.035)$.

Conclusions: Preoperative forced air-warming and warmed fluid prevents hypothermia and shivering in patients undergoing elective cesarean delivery with spinal anesthesia. (Korean J Anesthesiol 2012; 62: 454-460)

Key Words: Cesarean section, Shivering, Spinal anesthesia, Warming.

Received: July 14, 2011. Revised: 1st, August 4, 2011; 2nd, August 17, 2011; 3rd, August 22, 2011; 4th, September 16, 2011. Accepted: September 22, 2011. Corresponding author: Byung-Sang Lee, M.D., Department of Anesthesiology and Pain Medicine, CHA Gumi Medical Center, CHA University, 855, Hyunggok-dong, Gumi 730-040, Korea. Tel: 82-54-450-9686, Fax: 82-54-450-9990, E-mail: bsleemd@naver.com

@ This is an open-access article distributed under the terms of the Creative Commons Attribution Non-Commercial License (http:// creativecommons.org/licenses/by-nc/3.0/), which permits unrestricted non-commercial use, distribution, and reproduction in any medium, provided the original work is properly cited. 


\section{Introduction}

Shivering associated with spinal anesthesia occurs in up to $56.7 \%$ of patients [1]. In addition, perioperative shivering can occur in up to $85 \%$ of patients undergoing cesarean delivery under spinal anesthesia [2].

Postanesthetic shivering aggravates postoperative pain by stretching surgical incisions and also impedes monitoring techniques. Shivering increases intraocular and intracranial pressures, and is especially disturbing to mothers during labor and delivery [3]. Shivering also has many detrimental effects including increased oxygen consumption and hypoxemia [4].

Hypothermia during regional anesthesia is common [5] and is a cause of shivering. There are three reasons for hypothermia under spinal anesthesia. First, spinal anesthesia leads to internal redistribution of heat from the core to the peripheral compartment [6]. Secondly, with loss of thermoregulatory vasoconstriction below the level of the spinal block, there is increased heat loss from body surfaces. Lastly, there is altered thermoregulation under spinal anesthesia characterized by a $0.5^{\circ} \mathrm{C}$ decrease in vasoconstriction and shivering thresholds [7].

It is difficult to treat the core-to-peripheral redistribution of body heat [8]. However, redistribution can be prevented by preanesthetic cutaneous warming. Prewarming markedly increases peripheral tissue heat content and reduces the coreto-peripheral tissue temperature gradient [9], which affects temperature [10]. Woolnough et al. [11] found that prewarmed fluids reduced the decrease in maternal temperature and improved thermal comfort during cesarean section under combined spinal-epidural anesthesia, but did not affect shivering. Previous studies have shown that 15 min of forced-air prewarming, combined with intraoperative warming, prevents hypothermia and shivering during cesarean delivery under epidural anesthesia [12].

We tested the hypothesis that 15 min of forced-air prewarming or prewarmed fluids before spinal anesthesia prevents maternal hypothermia and shivering during cesarean section. We simultaneously evaluated the effect of these maternal prewarming methods on umbilical vein $\mathrm{pH}$ and Apgar scores in infants after birth.

\section{Materials and Methods}

After obtaining the approval of our Institutional Review Board and written informed consent from the patients, American Society of Anesthesiologists physical status I-II patients in the $38^{\text {th }}$ to $42^{\text {nd }}$ week of pregnancy who were supposed to undergo elective cesarean section were consecutively enrolled into the study. Pregnant women who had contraindication to spinal anesthesia; those who had accompanying gestational hypertension, placenta previa, and twin pregnancy; those whose weight was $<50 \mathrm{~kg}$ or $>100 \mathrm{~kg}$; those with fever; those with a recent history of any drugs except vitamins and minerals; and those who were converted to general anesthesia due to insufficient spinal anesthesia were excluded.

All patients were not premedicated and had fasted for at least $8 \mathrm{~h}$. A venous cannula was inserted into the forearm. For all the parturient women, an automated noninvasive blood pressure device was installed at the another arm, and a pulse oximeter and electrocardiograph were installed before the spinal anesthesia.

Patients' core temperatures were measured using a Thermoscan ${ }^{\circledR}$ (infrared tympanic thermometer IRT 4020; Braun, Bethlehem, PA, USA) in the same ear for repeated measurements. Temperatures were recorded to an average value of three measurements for accuracy. The same thermometer (with disposable sleeves) was used for all patients and readings were taken by the same operator. Skin temperatures of upper arm and thigh were measured using a Skin Temperature Probe ${ }^{\circledR}$ (REF 16560, 400 Series; Datex-Ohmeda, Teollisuuskatu, Finland). Temperatures were measured before and after 15 min warming and every 15 min after spinal anesthesia until the end of the operation.

Patients were randomly divided into three groups. Group F received a $10 \mathrm{ml} / \mathrm{kg}$ intravenous fluid preload of Hartmann's solution stored in a warming cabinet set at $40^{\circ} \mathrm{C}$ during the 15 min before spinal anesthesia and were applied with identical forced air-warming unit switched off. Our bench tests had shown that when $1 \mathrm{~L}$ bags of crystalloid, stored in the cabinet at this setting, were delivered through our standard giving set under gravity, the temperature of the fluid delivered at the distal end was $37-38^{\circ} \mathrm{C}$. Group A application involved an upper body forced air-warming unit (Bair Hugger ${ }^{\circledR}$; Augustine Medical, Eden Prairie, MN) using a Model 505 warming unit set at $43^{\circ} \mathrm{C}$ and received $10 \mathrm{ml} / \mathrm{kg}$ intravenous fluid preload of Hartmann's solution stored at room temperature during the 15 min before spinal anesthesia. Group C received a $10 \mathrm{ml} /$ $\mathrm{kg}$ intravenous fluid preload of Hartmann's solution stored at room temperature and were applied with identical forced airwarming unit switched off during the $15 \mathrm{~min}$ before spinal anesthesia.

Spinal anesthesia was performed in the right lateral position at the L3-4 interspace with a 26-gauge Whitacre needle by an anesthesiologist, with $10 \mathrm{mg}$ hyperbaric bupivacaine (Bupivacaine $\mathrm{HCl}^{\circledR}$; Myungmoon Pharmaceuticals, Seoul, Korea). Immediately after injecting the drug, the patients assumed a supine position and the uterus was transposed to the left by tilting the table by $15^{\circ}$ to the left, to prevent supine hypotensive syndrome. Block height was tested using an alcohol swab every minute until the height did not change. After 
finishing the drug injection through the subarachnoid space, the blood pressure was measured every 2 minutes. When the systolic blood pressure dropped below $100 \mathrm{mmHg}$ or decreased by more than $20 \%$ of the resting blood pressure, ephedrine (Ephedrine $\mathrm{HCl}$; Daewon Pharmaceuticals, Seoul, Korea) 8 mg was intravenously injected. When the blood pressure drop continued after the blood pressure measurement in 2-minute intervals, the same dose of ephedrine was repeatedly injected. The operation was initiated when the maximum sensory blockade level of the spinal anesthesia was T6 or higher and the blood pressure and heart rate of the parturient became stable after supine position.

Maternal data and observations, including core and skin temperature, nausea, vomiting, degree of shivering, thermal comfort, pain, heart rate, blood pressure, total fluids and blood loss were recorded. Umbilical vein blood from the infants was sampled for $\mathrm{pH}$ directly after birth. A pediatrician determined Apgar scores of the infants $1 \mathrm{~min}$ after birth.

Shivering was graded during and after cesarean section using an existing scale [13]: $0=$ no shivering; 1 = one or more of the following: piloerection, peripheral vasoconstriction or peripheral cyanosis without other cause, but without visible muscular activity; 2 = visible muscular activity confined to one muscle group; and 4 = gross muscular activity involving the whole body. Thermal comfort after the cesarean delivery was evaluated with $100 \mathrm{~mm}$ VAS on which $0 \mathrm{~mm}$ was defined as insufferably hot, $50 \mathrm{~mm}$ as thermally neutral and $100 \mathrm{~mm}$ as worst imaginable cold.

Table 1. Demographic Data

\begin{tabular}{lccc}
\hline & $\begin{array}{c}\text { Group C } \\
(\mathrm{n}=15)\end{array}$ & $\begin{array}{c}\text { Group F } \\
(\mathrm{n}=15)\end{array}$ & $\begin{array}{c}\text { Group A } \\
(\mathrm{n}=15)\end{array}$ \\
\hline Age (yr) & $31.9 \pm 4.6$ & $32.5 \pm 3.4$ & $31.8 \pm 3.9$ \\
Weight (kg) & $67.0 \pm 9.9$ & $68.0 \pm 11.6$ & $68.8 \pm 10.4$ \\
Height (cm) & $159.6 \pm 7.1$ & $157.3 \pm 6.4$ & $159.6 \pm 5.6$ \\
Gestational age (day) & $266.9 \pm 5.0$ & $266.7 \pm 5.3$ & $268.6 \pm 5.5$ \\
\hline
\end{tabular}

Values are mean \pm SD. There are no statistically differences among the three groups. Group A: forced-air prewarming group, Group C: control group, Group F: intravenous warmed fluids groups.

Table 2. Surgical and Spinal Anesthesia Data

\begin{tabular}{lccc}
\hline & $\begin{array}{c}\text { Group C } \\
(\mathrm{n}=15)\end{array}$ & $\begin{array}{c}\text { Group F } \\
(\mathrm{n}=15)\end{array}$ & $\begin{array}{c}\text { Group A } \\
(\mathrm{n}=15)\end{array}$ \\
\hline Spinal level (thoratic) & $\mathrm{T} 4(\mathrm{~T} 2-\mathrm{T} 6)$ & $\mathrm{T} 4(\mathrm{~T} 2-\mathrm{T} 6)$ & $\mathrm{T} 4(\mathrm{~T} 2-\mathrm{T} 6)$ \\
Total fluid (ml) & $1,140 \pm 140$ & $1,197 \pm 215$ & $1,210 \pm 120$ \\
Blood loss (ml) & $540 \pm 112$ & $507 \pm 139$ & $587 \pm 141$ \\
Ephedrine (mg) & $10.7 \pm 11.2$ & $16.3 \pm 14.7$ & $14.4 \pm 11.0$ \\
Duration of surgery (min) & $43.0 \pm 8.2$ & $41.5 \pm 7.2$ & $45.7 \pm 7.3$ \\
\hline
\end{tabular}

Values are mean \pm SD. There are no statistically differences among the three groups. Group A: forced-air prewarming group, Group C: control group, Group F: intravenous warmed fluids groups.
We studied 45 healthy pregnant women. Indications for cesarean delivery included previous cesarean delivery and breech presentation. None of the parturients was in labor. The sample size of 15 per group was set according to power analysis based on values for $\alpha$ of 0.05 and $\beta$ of 0.1 , and data from a previous study [12]. The sample size for this study was based on an expected treatment effect of $1^{\circ} \mathrm{C}$ with a standard deviation of $0.5^{\circ} \mathrm{C}$ (calculated sample size of nine). Forty five participants were estimated to provide $90 \%$ power.

Descriptive statistics were used to summarize demographic, outcome and side effect data. Data are expressed as mean $\pm \mathrm{SD}$, median (range) and numbers or percentages as appropriate. Outcome measures between the three groups were compared using analysis of variance and Duncan grouping to determine differences. Associations among discrete variables were investigated using Pearson's $\chi^{2}$ test or Fisher's exact test. Analyses were performed with SPSS 19.0 statistical package (SPSS, Chicago, IL, USA). A P value $<0.05$ was considered statistically significant.

\section{Results}

Maternal demographic and obstetric data were similar among the groups (Table 1). There was no difference among the groups with regard to the median level of sensory block, duration of surgery and ephedrine dose administered (Table 2). Surgical and anesthetic characteristics are summarized in Table 2. No spinal block failures or surgical complications requiring conversion to general anesthesia were encountered.

The core temperature at 45 min decreased less in Group $\mathrm{F}$ and Group A than Group $\mathrm{C}\left(-0.5^{\circ} \mathrm{C} \pm 0.3^{\circ} \mathrm{C}\right.$ vs $-0.6^{\circ} \mathrm{C} \pm 0.4^{\circ} \mathrm{C}$ vs $-0.9^{\circ} \mathrm{C} \pm 0.4^{\circ} \mathrm{C}$, respectively; $\mathrm{P}=0.004$ ) (Fig. 1). The arm

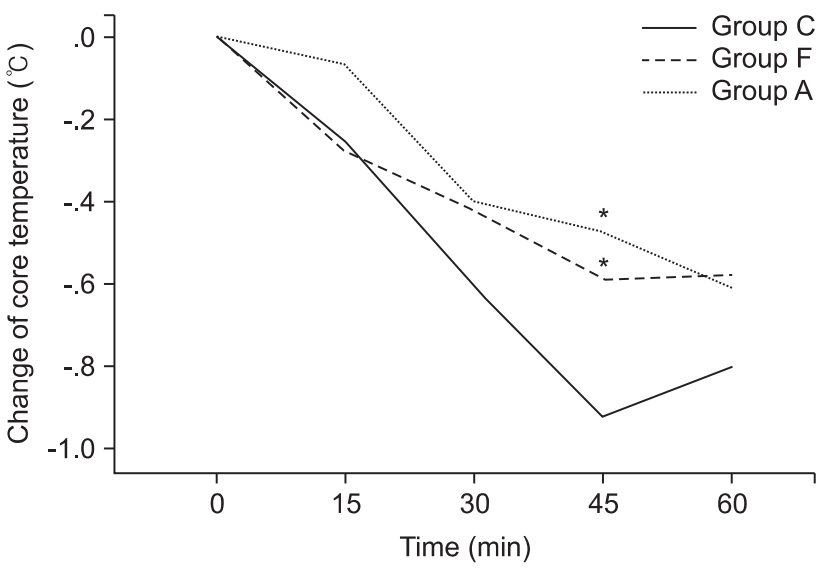

Fig. 1. Changes in core temperature after prewarming $(\mathrm{t}=0 \mathrm{~min})$ and spinal anesthesia $(t=15 \mathrm{~min})$. Data are expressed as mean. The value after 45 min significantly decreased less in Group F and Group A than Group. Group A: forced-air prewarming group, Group C: control group, Group F: intravenous warmed fluids group. ${ }^{*} \mathrm{P}=0.004$. 


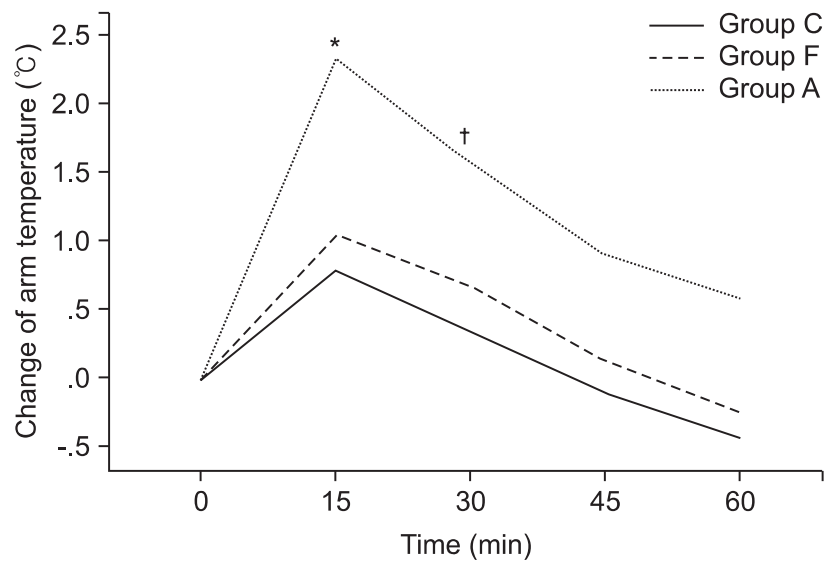

Fig. 2. Changes in arm temperature after prewarming $(t=0 \mathrm{~min})$ and spinal anesthesia $(\mathrm{t}=15 \mathrm{~min})$. Data are expressed as mean. The values at $15 \mathrm{~min}$ and $30 \mathrm{~min}$ significantly exhibited greater increase in Group A than Group F and Group C. Group A: forced-air prewarming group, Group C: control group, Group F: intravenous warmed fluids group. $* \mathrm{P}=0.001,{ }^{\dagger} \mathrm{P}=0.012$.

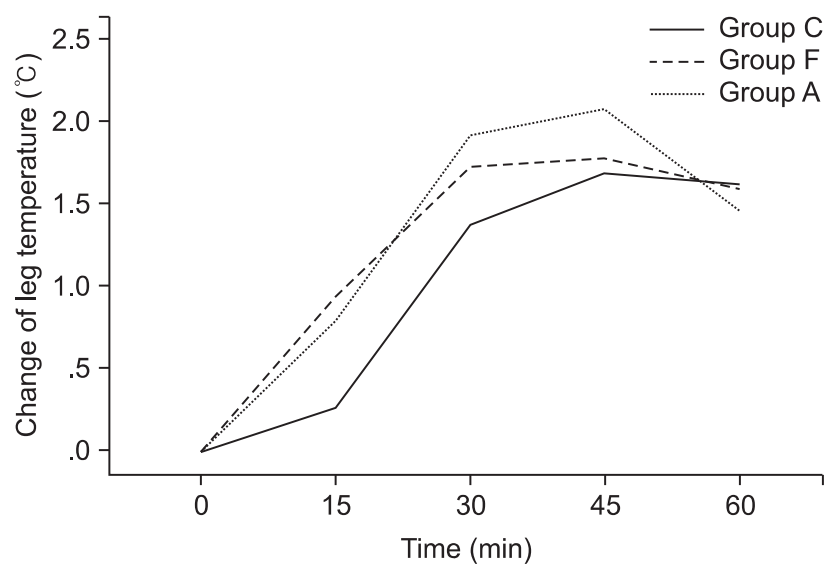

Fig. 3. Changes in leg temperature after prewarming $(t=0 \mathrm{~min})$ and spinal anesthesia $(t=15 \mathrm{~min})$. Data are expressed as mean. There is no significantly difference among the three groups. Group A: forcedair prewarming group, Group C: control group, Group F: intravenous warmed fluids group.

temperature at $15 \mathrm{~min}$ and $30 \mathrm{~min}$ exhibited a greater increase in Group A than Group F and Group C $\left(15 \mathrm{~min} ; 2.3^{\circ} \mathrm{C} \pm 1.5^{\circ} \mathrm{C}\right.$ vs $1.1^{\circ} \mathrm{C} \pm 0.7^{\circ} \mathrm{C}$ vs $0.8^{\circ} \mathrm{C} \pm 1.0^{\circ} \mathrm{C}$, respectively; $\mathrm{P}=0.001,30 \mathrm{~min}$; $1.6^{\circ} \mathrm{C} \pm 1.5^{\circ} \mathrm{C}$ vs $0.7^{\circ} \mathrm{C} \pm 0.6^{\circ} \mathrm{C}$ vs $0.3^{\circ} \mathrm{C} \pm 1.0^{\circ} \mathrm{C}$, respectively; $\mathrm{P}=$ 0.012) (Fig. 2). The leg temperature increased similarly among the three groups (Fig. 3).

Shivering was observed in eight (53.3\%) of 15 patients without prewarming. An incidence of shivering was significantly reduced to only two (13.3\%) of 15 in the patients with intravenous warmed fluids and to only three (20\%) of 15 patients with forced-air prewarming (Fig. 4).

Thermal comfort scores were clinically higher in Group C

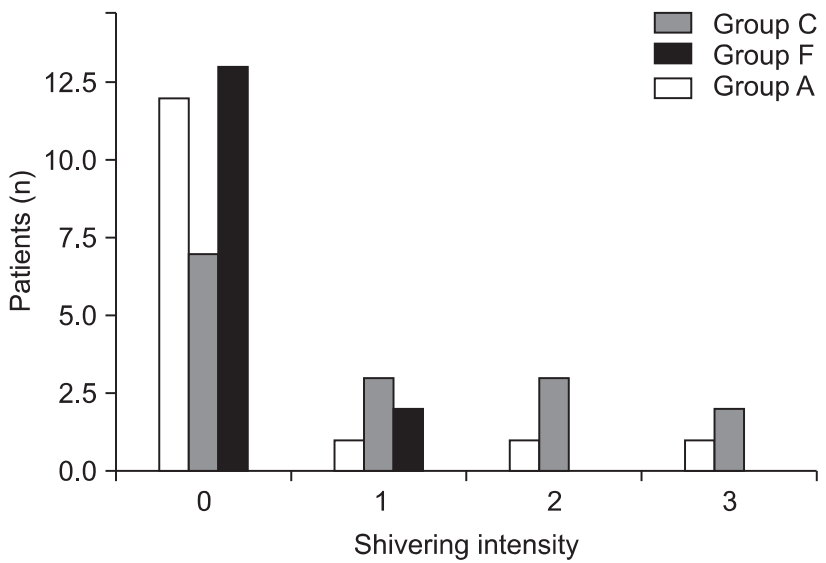

Fig. 4. Patients who experienced each response at any time. The shivering incidence of group A, group $\mathrm{F}$ and group $\mathrm{C}$ were $3 / 15(20 \%)$, $2 / 15(13.3 \%)$ and $8 / 15(53.3 \%)$. There is significantly difference among the three groups $(\mathrm{P}=0.035)$. Group A: forced-air prewarming group, Group C: control group, Group F: intravenous warmed fluids groups.

Table 3. Thermal Comfort and Infant Data

\begin{tabular}{lcccc}
\hline & $\begin{array}{c}\text { Group C } \\
(\mathrm{n}=15)\end{array}$ & $\begin{array}{c}\text { Group F } \\
(\mathrm{n}=15)\end{array}$ & $\begin{array}{c}\text { Group A } \\
(\mathrm{n}=15)\end{array}$ & P value \\
\hline Cold VAS & $69.0 \pm 15.9$ & $59.3 \pm 13.2$ & $59.0 \pm 12.1$ & 0.093 \\
Umbilical vein $\mathrm{pH}$ & $7.35 \pm 0.04$ & $7.33 \pm 0.06$ & $7.32 \pm 0.04$ & 0.349 \\
Apgar score & $8.20 \pm 0.86$ & $8.07 \pm 1.10$ & $8.13 \pm 0.83$ & 0.927
\end{tabular}

Values are mean \pm SD. There are no statistically differences among the three groups. Group A: forced-air prewarming group, Group C: control group, Group F: intravenous warmed fluids groups.

$(69.0 \pm 15.9)$ than Group A $(59.0 \pm 12.1)$ and F $(59.3 \pm 13.2)$ (P $=0.093)$. But, the Scores did not differ statistically among the three groups. Umbilical vein $\mathrm{pH}$ and Apgar scores were similar in the three groups (Table 3 ).

\section{Discussion}

In our study, preoperative upper body forced-air warming and intravenous warmed fluids reduced the perioperative hypothermia and incidence of shivering in patients undergoing cesarean section with spinal anesthesia compared with control group without prewarming.

Redistribution of body heat is the major initial cause of hypothermia in patients with neuraxial anesthesia [14]. Neuraxial anesthesia also inhibits thermoregulatory control centrally and blocks peripheral sympathetic and motor nerve, which prevents thermoregulatory vasoconstriction and shivering [15-17]. Core temperature decreased $0.8 \pm 0.3^{\circ} \mathrm{C}$ in the first hour of neuraxial anesthesia. Redistribution during neuraxial anesthesia contributes $89 \%$ to this initial decrease and is typically 
restricted to the leg [6]. After an initial decrease, sufficient core hypothermia will trigger vasoconstriction and shivering in unblocked regions. But, upper body shivering is relatively ineffective and insufficient to prevent further hypothermia [14]. Shivering can double or even triple oxygen consumption and carbon dioxide production. These large increases in metabolic requirement might predispose lactic acidosis and hypoxemia [3]. Those effects are particularly bothersome in the obstetrical population.

Although hypothermia during regional anesthesia is common and severe because of the aforementioned mechanism, abnormal tolerance for shivering is observed [15] and lower core temperatures than usual are required to trigger shivering during regional anesthesia [18]. Regional anesthesia significantly increases apparent leg skin temperature to a level far exceeding the actual leg temperature and the increased apparent skin temperature decreases the threshold at which shivering is initiated [15]. In addition, the shivering threshold is reduced about $0.6^{\circ} \mathrm{C}$ by spinal anesthesia [17]. In this study, we confirmed that, although shivering threshold related to increased leg skin temperature was reduced, the control group, in which core temperature reduced over $0.6^{\circ} \mathrm{C}$, had a significantly higher incidence of shivering. Therefore, it is important to maintain core temperature over decreased shivering threshold during spinal anesthesia for lower incidence of shivering.

Previous studies have described several methods to prevent perioperative shivering during regional anesthesia. Kelsaka et al. [19] compared the efficacy of ondansetron and meperidine in the prevention of shivering during and after spinal anesthesia. They reported that shivering was lower in the ondansetron and meperidine groups than in the control group. Honarmand and Safavi [20] showed that the prophylactic use of ketamine $(0.25$ $\mathrm{mg} / \mathrm{kg})$ and midazolam $(3.75 \mu \mathrm{g} / \mathrm{kg})$ was effective in preventing shivering developed during regional anesthesia. Actually, these pharmacological treatments for shivering are limited in parturients during cesarean section under spinal anesthesia because it is possible for the drugs to have an influence on newborn outcomes.

In another study, Roy et al. [2] reported that intrathecal meperidine $(0.2 \mathrm{mg} / \mathrm{kg})$ is effective in reducing the incidence and intensity of shivering associated with spinal anesthesia for cesarean section. Although side effects of intrathecal meperidine were dose related, transient neurological symptoms [21], nausea, vomiting, pruritus and respiratory depression [22] were reported. Many questions still remain unanswered, including the optimal dose of intrathecal meperidine to prevent shivering in patients during cesarean section.

Forced air-warming devices are commonly used to prevent intraoperative hypothermia. A previous study showed that patients undergoing cesarean delivery with epidural anesthesia experience less hypothermia and shivering if forced air-warming is used in the preoperative and intraoperative periods [12]. But, Butwick et al. [23] concluded that intraoperative lower body forced air-warming does not prevent intraoperative hypothermia or shivering in women undergoing elective cesarean delivery with spinal anesthesia. So, we realized that preoperative warming was more important than intraoperative warming and upper body warming was more effective than lower body warming. Prewarming hardly changes core temperature, which remains well regulated, but it markedly increases peripheral tissue heat content [9]. As a result, prewarming reduces the core to peripheral tissue temperature gradient and the propensity for redistribution after the induction of anesthesia. In addition, intraoperative upper body forced air-warming is uncomfortable and may interfere with early maternal-newborn bonding [24]. In this study, we found that a brief period of preoperative upper body forced air-warming, such as 15 min before operation start, was easy to accommodate and reduced maternal hypothermia and incidence of shivering during cesarean section with spinal anesthesia.

Unlike forced air-warming, warming intravenous fluids during elective cesarean section does not disturb the operation. Workhoven [10] reported that warming intravenous fluids reduced the incidence and severity of shivering without significantly affecting temperature. But, Woolnough et al. [11] showed that prewarmed fluids did not affect shivering. So, we studied the effect of preoperative warmed fluid preload on incidence of shivering during cesarean section under spinal anesthesia in this study. We used $37-38^{\circ} \mathrm{C}$ warmed fluid at the distal end and there were no complications like vessel injury in this temperature [11]. Our results suggest that preoperative warmed fluid preload was as efficient as using forced airwarming and similarly reduced maternal hypothermia and shivering. The difference between two methods was that the arm temperature was higher in forced air-warming group than the warmed fluid group. Therefore, we suggest that although there are different mechanisms for reducing hypothermia between two methods, the decrease of core temperature and the incidence of shivering were similar in patients of both groups during cesarean section under spinal anesthesia.

Previous studies have shown that intraoperative maternal forced air-warming is not beneficial in improving umbilical vein $\mathrm{pH}$ and Apgar score of the infants after birth [23,25]. But, Horn et al. [12] reported that preoperative forced air-warming combined with intraoperative warming improved the umbilical vein $\mathrm{pH}$ and rectal temperatures of the newborns without difference of Apgar score. In this study, we confirmed that only 15 min prewarming using forced air-warming or warmed fluid did not improve newborn outcomes. We guessed that $15 \mathrm{~min}$ 
prewarming was an insufficient period to influence the infants after birth. Maternal hypothermia is likely to develop more rapidly during spinal anesthesia than epidural anesthesia. But, the intensity of shivering was reduced during spinal anesthesia, and the shivering threshold was significantly less during spinal anesthesia than epidural anesthesia because thermoregulation is known to be impaired more by spinal anesthesia than by epidural anesthesia [26]. In addition, extensive spinal block impairs central thermoregulatory control more than less extensive block. That is, reduction in the shivering threshold is proportional to spinal block height [27]. Especially, during cesarean section under spinal anesthesia, a patient requires an extensive spinal block over the T4 level, but the duration of spinal anesthesia is not long because of the use of a small dose of hyperbaric bupivacaine. Therefore, although the shivering threshold is reduced, maternal hypothermia keeps developing during cesarean section and then the shivering occurs after 45 or $60 \mathrm{~min}$ of spinal anesthesia.

Interestingly, Szmuk et al. [28] reported that regidual spinal anesthesia, which maintained lower body vasodilation, significantly increased the rate of core rewarming. Vasodilation facilitates core rewarming in patients after operation with residual lower body sympathetic blocks. We suggest that residual vasodilation in patients after cesarean section under spinal anesthesia will facilitate the core rewarming and the incidence of shivering will decrease if rewarming using forced air-warming is applied immediately after cesarean section.

In summary, preoperative forced air-warming and warmed fluid prevented maternal core hypothermia and reduces maternal shivering in patients during cesarean section under spinal anesthesia. Those two warming methods are not effective enough to improve newborn outcome and maternal thermal comfort.

\section{References}

1. Chen JC, Hsu SW, Hu LH, Hong YJ, Tsai PS, Lin TC, et al. Intrathecal meperidine attenuates shivering induced by spinal anesthesia. Ma Zui Xue Za Zhi 1993; 31: 19-24.

2. Roy JD, Girard M, Drolet P. Intrathecal meperidine decreases shivering during cesarean delivery under spinal anesthesia. Anesth Analg 2004; 98: 230-4.

3. De Witte J, Sessler DI. Perioperative shivering: physiology and pharmacology. Anesthesiology 2002; 96: 467-84.

4. Macintyre PE, Pavlin EG, Dwersteg JF. Effect of meperidine on oxygen consumption, carbon dioxide production, and respiratory gas exchange in postanesthesia shivering. Anesth Analg 1987; 66: 751-5.

5. Frank SM, Beattie C, Christopherson R, Norris EJ, Rock P, Parker $\mathrm{S}$, et al. Epidural versus general anesthesia, ambient operating room temperature, and patient age as predictors of inadvertent hypothermia. Anesthesiology 1992; 77: 252-7.

6. Matsukawa T, Sessler DI, Christensen R, Ozaki M, Schroeder M. Heat flow and distribution during epidural anesthesia. Anesthesiology 1995; 83: 961-7.

7. Ozaki M, Kurz A, Sessler DI, Lenhardt R, Schroeder M, Moayeri A, et al. Thermoregulatory thresholds during epidural and spinal anesthesia. Anesthesiology 1994; 81: 282-8.

8. Hynson JM, Sessler DI. Intraoperative warming therapies: a comparison of three devices. J Clin Anesth 1992; 4: 194-9.

9. Hynson JM, Sessler DI, Moayeri A, McGuire J, Schroeder M. The effects of preinduction warming on temperature and blood pressure during propofol/nitrous oxide anesthesia. Anesthesiology 1993; 79: 219-28.

10. Workhoven MN. Intravenous fluid temperature, shivering, and the parturient. Anesth Analg 1986; 65: 496-8.

11. Woolnough M, Allam J, Hemingway C, Cox M, Yentis SM. Intraoperative fluid warming in elective caesarean section: a blinded randomised controlled trial. Int J Obstet Anesth 2009; 18: 346-51.

12. Horn EP, Schroeder F, Gottschalk A, Sessler DI, Hiltmeyer N, Standl $\mathrm{T}$, et al. Active warming during cesarean delivery. Anesth Analg 2002; 94: 409-14.

13. Wrench IJ, Cavill G, Ward JE, Crossley AW. Comparison between alfentanil, pethidine and placebo in the treatment of postanaesthetic shivering. Br J Anaesth 1997; 79: 541-2.

14. Sessler DI. Perioperative heat balance. Anesthesiology 2000; 92: 578-96.

15. Emerick TH, Ozaki M, Sessler DI, Walters K, Schroeder M. Epidural anesthesia increases apparent leg temperature and decreases the shivering threshold. Anesthesiology 1994; 81: 289-98.

16. Hopf HB, Weissbach B, Peters J. High thoracic segmental epidural anesthesia diminishes sympathetic outflow to the legs, despite restriction of sensory blockade to the upper thorax. Anesthesiology 1990; 73: 882-9.

17. Kurz A, Sessler DI, Schroeder M, Kurz M. Thermoregulatory response thresholds during spinal anesthesia. Anesth Analg 1993; 77: 721-6.

18. Roe CF, Cohn FL. The causes of hypothermia during spinal anesthesia. Surg Gynecol Obstet 1972; 135: 577-80.

19. Kelsaka E, Baris S, Karakaya D, Sarihasan B. Comparison of ondansetron and meperidine for prevention of shivering in patients undergoing spinal anesthesia. Reg Anesth Pain Med 2006; 31: 40-5.

20. Honarmand A, Safavi MR. Comparison of prophylactic use of midazolam, ketamine, and ketamine plus midazolam for prevention of shivering during regional anaesthesia: a randomized double-blind placebo controlled trial. Br J Anaesth 2008; 101: 557 62.

21. Lewis WR, Perrino AC Jr. Transient neurological symptoms after subarachnoid meperidine. Anesth Analg 2002; 94: 213-4.

22. Ong B, Segstro R. Respiratory depression associated with meperidine spinal anaesthesia. Can J Anaesth 1994; 41: 725-7.

23. Butwick AJ, Lipman SS, Carvalho B. Intraoperative forced airwarming during cesarean delivery under spinal anesthesia does not prevent maternal hypothermia. Anesth Analg 2007; 105: 1413-9.

24. Petsas A, Vollmer H, Barnes R. Peri-operative warming in Caesarean sections. Anaesthesia 2009; 64: 921-2.

25. Fallis WM, Hamelin K, Symonds J, Wang X. Maternal and newborn 
outcomes related to maternal warming during cesarean delivery. J Obstet Gynecol Neonatal Nurs 2006; 35: 324-31.

26. Saito T, Sessler DI, Fujita K, Ooi Y, Jeffrey R. Thermoregulatory effects of spinal and epidural anesthesia during cesarean delivery. Reg Anesth Pain Med 1998; 23: 418-23.

27. Leslie K, Sessler DI. Reduction in the shivering threshold is proportional to spinal block height. Anesthesiology 1996; 84: 132731 .

28. Szmuk P, Ezri T, Sessler DI, Stein A, Geva D. Spinal anesthesia speeds active postoperative rewarming. Anesthesiology 1997; 87: 1050-4. 